\title{
Susceptibility Pattern of Gram Negative Urine Pathogens with Exclusion of Escherichia coli to Quinolone/ Fluoroquinolone Antibiotics
}

\author{
Bharat Sapkota ${ }^{1,4}$ Ram Krishna Bhandari ${ }^{2}$ and Bishnu Raj Tiwari ${ }^{3}$ \\ ${ }^{I}$ Department of Microbiology, Tri-Chandra Multiple Campus, Trivuban University, Kathmandu \\ ${ }^{2}$ National Public Health Laboratory, Kathmandu \\ Department of Microbiology, School of Health and Allied Science, Pokhara University, Nepal \\ ${ }^{4}$ Microbiology and Molecular Biology Research Association, Kathmandu, Nepal \\ e-mail: sapkotabharat7@gmail.com
}

\begin{abstract}
Quinolone/Fluoroquinolones group of antibiotics are frequently used for the treatment of urinary tract infection (UTI). Because of high frequency of Gram negative bacterial infection in UTI and emerging resistant urinary pathogen in spite of lower prevalence with exclusion of Escherichia coli, the susceptibility pattern was subjected in this study. The study was conducted at National Public Health Laboratory (NPHL) Teku, Kathmandu with an objective to study the antibiotic Quinolone/Fluoroquinolones susceptibility pattern.Out of 550 urine samples, 100 $(18.18 \%)$ bacteria were isolated from NPHL. Also, 69 isolates from Blue-Cross Hospital and 83 isolates from Medicare Hospital were collected. Altogether 252 urine isolates, showing significant growth in MacConkey Agar and blood agar were identified by standard microbiological techniques. Among 62 Gram negative isolates other than Escherichia coli subjected for the study; Proteus mirabilis (27.42\%), Proteus vulgaris (11.29\%), Klebsiella oxytoca (12.90\%), Klebsiella pneumoniae (17.75\%), Citrobacter freundii (8.06\%), Enteribacter cloaecae (6.45\%), Pseudomonas aeruginosa (12.90\%), Acinetobacter spp. (3.23\%). Altogether eight types of antibiotics belonging to quinolone/fluoroquinolone group were used in this study. Among them, norfloxacin was found most sensitive and nalidixic acid was most resistant against Gram negative isolates.
\end{abstract}

Key words: AST, Gram negative, Quinolone/Fluroquinolone, urinary tract infection

\section{Introduction}

Urinary tract infection (UTI) simply means the presence of bacteria undergoing multiplication in human urine within the urinary drainage system (Leigh 1990). From a microbiological perspective, UTI exists when pathogenic microorganisms are detected in the urine, urethra, bladder, kidney or prostate. In most instances, growth of more than $10^{5}$ organisms per milliliter from a properly collected midstream "cleancatch" urine sample indicates infection (Stamm 2003). There are wide varieties of Gram positive and Gram negative organisms that cause the UTI. Among Gram negative E. coli is the most common cause of UTI.Such as Pseudomonas spp., Proteus spp., Klebsiella spp., and Staphylococcus aureus are generally associated with hospital acquired infection followed by catherization and gynecological surgery. Infections due to Proteus spp. are associated with renal stones. Staphylococcus saprophyticus infection is usually found in sexually active women (Forbes et al. 2002).

There has been a recent dramatic growth in information on the use of fluoroquinolone antimicrobial agents for the oral treatment of bacterial infections of the 
genitourinary tract. The fluoroquinolones include norfloxacin, ciprofloxacin, ofloxacin, non fluorinated agent nalidixic acid. The low risk of nephrotoxicity of antibiotics in patients with complicated urinary tract infection may be especially advantageous (Fluit et al. 2004).

The quinolones also referred to as fluoroquinolones are a family of synthetic broad-spectrum antibiotics. The first generation of the quinolone begins with the introduction of nalidixic acid in 1962 for the treatment of urinary tract infections in humans (Denyer et al. 2007). Quinolones or fluoroquinolones, some of the most frequently prescribed antimicrobial agents worldwide target the bacterial type II Topoisomerase, Gyrase and Topoisomerase IV. Fluoroquinolones increase the longetivity of the normally short-lived cleaved DNA topoisomerase intermediates. DNA tracking machinery somehow is affected by these intermediates, resulting in multiple subsequent effects, such as chromosome fragmentation, the inhibition of DNA synthesis and death (Lauren 2009).

The fluoroquinolones resistance is acquired by changes in outer-membrane permeability for gram negatives organisms. Efflux, however, does contribute to resistance mainly low level for both Gram positive and Gram negative bacteria (Denyer et al. 2007).

\section{Methodology}

This study was conducted at the National Public Health Laboratory, Kathmandu, Teku from Sep, 2009-Mar, 2010. Cross-sectional study was performed.

\section{Sample collection and transport}

Each patient was given a sterile dry, wide-naked leak proof container and requested for 10-20 ml mid-stream urine sample. He/She was instructed properly for collecting mid stream urine sample before providing the container. The clinical urine samples were collected from Medicare Hospital and Blue-Cross Nursing home by sub-culturing on nutrient agar (NA) slants.

\section{Culture of sample}

The urine samples were cultured into the MacConkey agar and blood agar medium by semi-quantitative culture technique using standard loop to detect the presence of significant bacteriuria (Cheesbrough 2000).

\section{Identification of isolates}

Standard protocols provided by (Cheesbrough 2000) and (Collee 1996) were followed for identification of bacteria isolated from urine specimens.

\section{Antibiotic susceptibility testing (AST)}

According to protocols of (Vandepitte et al. 2003) and (Sapkota et al. 2014), the tests were performed.

\section{Selected antibiotics for AST}

Antibiotics used for UTI from quinolone/ fluoroquinolone group were Nalidixic acid (NA), Moxifloxacin (MFX), Levofloxacin (LEV), Gatifloxacin(GAT), Ofloxacin (OF), Ciprofloxacin (CIP), Norfloxacin (NOR) and Enrofloxacin (ENF).

\section{Data analysis}

The data were analyzed by statistical package for social science (SPSS) software version 16.0 and One-way ANOVA.

\section{Results and Discussion}

During the study period, a total of 550 patients suspected of urinary tract infection visiting National public Health Laboratory (NPHL), were included for urine culture. One hundred isolates from NPHL, 83 isolates from Medicare Hospital and (69) isolates from Blue-Cross Nursing home were the sources of the selected isolates used for antibiotic sensitivity testing.

The total Gram negative isolates were 62 excluding E.coli. Most isolates were Proteus mirabils (27.42 $\%)$ and least were Acinetobacter spp. (3.23\%).

Table 1. Total bacterial isolates from urine culture

\begin{tabular}{l|c|c}
\hline \multicolumn{3}{|c}{ Bacterial isolates of UTI } \\
\hline $\begin{array}{l}\text { Gram negative isolates } \\
(61.51 \%)\end{array}$ & $\begin{array}{l}\text { No. of } \\
\text { isolates }\end{array}$ & $\begin{array}{l}\text { Percentage } \\
(\%)\end{array}$ \\
\hline Proteus nilgaris & 7 & 11.29 \\
Proteus mirabils & 17 & 27.42 \\
Klebsella oxytoca & 8 & 12.90 \\
Kelbsella pneumoniae & 11 & 17.75 \\
Citrobacter fremdii & 5 & 8.06 \\
Enterobacter cloaecae & 4 & 6.45 \\
Pseudomonas aerogionosa & 8 & 12.90 \\
Acinetobacter spp. & 2 & 3.23 \\
Total Gram negative isolates & 62 & 100 \\
\hline
\end{tabular}


Bharat Sapkota et al/Susceptibility Pattern of Gram.

Table 2. QuinolonelFluoroquinolone sensitivity pattern of $P$. vulgaris

\begin{tabular}{|c|c|c|c|c|c|c|c|}
\hline \multirow{2}{*}{$\begin{array}{l}\text { Groups of } \\
\text { antibiotics }\end{array}$} & & \multicolumn{2}{|c|}{ Resistant } & \multicolumn{2}{|c|}{ Intermediate } & \multicolumn{2}{|c|}{ Sensitive } \\
\hline & Antbiotic & Isolates & $\%$ & Isolates & $\%$ & Isolates & $\%$ \\
\hline $\begin{array}{l}\text { Quinolonelfhoroq } \\
\text { uinolone }\end{array}$ & $\mathrm{HA}$ & 5 & 71.43 & 0 & 0 & 2 & 28.57 \\
\hline & MFX & 3 & 42.86 & 0 & 0 & 4 & 57.14 \\
\hline & ENF & 5 & 71.43 & 0 & 0 & 2 & 28.57 \\
\hline & LEV & 5 & 71.43 & 0 & 0 & 2 & 28.57 \\
\hline & GAT & 3 & 42.86 & 0 & 0 & 4 & 57.14 \\
\hline & oFX & 3 & 42.86 & 2 & 28.57 & 2 & 28.57 \\
\hline & CIP & 5 & 71.43 & 0 & 0 & 2 & 28.57 \\
\hline & $\mathrm{HOR}$ & 2 & 28.57 & 0 & 0 & 5 & 71.43 \\
\hline
\end{tabular}

In Quinolone/Fluoroquinolones group of antibiotics Nalidixic acid, Enrofloxacin, Levofloxacin and Ciprofloxacin showed similar resistance pattern i.e., $71.43 \%$. Norfloxacin $(71.43 \%)$ was found to be more sensitive towards the isolates in this study.
In QuinolonelFluoroquinolones group, Nalidixic acid was found most resistant $(76.47 \%)$ whereas Norfloxacin was found most sensitive $(82.35 \%)$ and Gatifloxacin and Ciprofloxacin were sensitive $(76.47 \%)$ towards isolates.

Table 3. QuinolonelFluoroquinolone sensitivity pattern of $\boldsymbol{P}$. mirabilis

\begin{tabular}{|c|c|c|c|c|c|c|c|}
\hline \multicolumn{8}{|c|}{ Froteus mirabils $(\mathrm{n}=17)$} \\
\hline \multirow{10}{*}{$\begin{array}{l}\text { Antbiotics } \\
\text { groups } \\
\text { Quinolone Fhor } \\
\text { oquinolone }\end{array}$} & \multirow[b]{2}{*}{ Antibiotics } & \multicolumn{2}{|c|}{ Resistant } & \multicolumn{2}{|c|}{ Inte mediate } & \multicolumn{2}{|c|}{ Sersitive } \\
\hline & & Isolates & $\%$ & Isolates & $\%$ & Isolates & $\%$ \\
\hline & NA & 13 & 76.47 & 3 & 17.65 & 1 & 5.88 \\
\hline & $\mathrm{MFX}$ & 6 & 35.29 & 0 & 0.00 & 11 & 64.71 \\
\hline & ENF & 4 & 23.53 & 1 & 5.88 & 12 & 70.59 \\
\hline & LEV & 4 & 23.53 & 0 & 0.00 & 13 & 76.47 \\
\hline & GAT & 2 & 11.76 & 2 & 11.76 & 13 & 76.47 \\
\hline & OFX & 5 & 29.41 & 2 & 11.76 & 10 & 58.82 \\
\hline & CIP & 2 & 11.76 & 3 & 17.65 & 12 & 70.59 \\
\hline & HOR & 2 & 11.76 & 1 & 5.88 & 14 & 82.35 \\
\hline
\end{tabular}

Table 4. QuinolonelFluoroquinolone sensitivity pattern of $K$. oxytoca

\begin{tabular}{|c|c|c|c|c|c|c|c|}
\hline \multicolumn{8}{|c|}{ Klebsiella oxytoca $(\mathrm{n}=8)$} \\
\hline Antibiotics group & Antibiotic & Resistant & & Inte rmediate & & Sersitive & \\
\hline \multirow{9}{*}{$\begin{array}{l}\text { QuinolonelFluoroqu } \\
\text { inolones }\end{array}$} & & Isolates & $\%$ & Isolates & $\%$ & Isolates & $\%$ \\
\hline & NA & 3 & 37.50 & 0 & 0.00 & 5 & 62.50 \\
\hline & MFX & 4 & 50.00 & 0 & 0.00 & 4 & 50.00 \\
\hline & ENF & 3 & 37.50 & 0 & 0.00 & 5 & 62.50 \\
\hline & LEV & 3 & 37.50 & 0 & 0.00 & 5 & 62.50 \\
\hline & GAT & 3 & 37.50 & 0 & 0.00 & 5 & 62.50 \\
\hline & OFX & 3 & 37.50 & 0 & 0.00 & 5 & 62.50 \\
\hline & CIP & 3 & 37.50 & 0 & 0.00 & 5 & 62.50 \\
\hline & $\mathrm{NOR}$ & 2 & 25.00 & 0 & 0.00 & 6 & 75.00 \\
\hline
\end{tabular}


Among Quinolonelfluoroquinolone, the isolates were sensitive towards Norfloxacin where as resiatance towards Nalidixic acid, Moxifloxacin, Enrofloxacin, Levofloxacin, Gatiflixacin, Ofloxacin, Ciprofloxacin.

Table 5. QuinolonelFluoroquinolone sensitivity pattern of $K$. pneumonia

\begin{tabular}{|c|c|c|c|c|c|c|c|}
\hline \multicolumn{8}{|c|}{ Rebsiella pne umoniae $(\mathrm{n}=11)$} \\
\hline Antibiotics & Antibiotic & Resistant & & Intermediate & & Sensitive & \\
\hline \multirow{9}{*}{$\begin{array}{l}\text { Quinolome Fluor } \\
\text { oquinolones }\end{array}$} & & Eolates & $\%$ & Eolates & $\%$ & Isolates & $\%$ \\
\hline & $\mathrm{HA}$ & 8 & 72.73 & 0 & 0.00 & 3 & 27.27 \\
\hline & MFX & 6 & 54.55 & 2 & 18.18 & 3 & 27.27 \\
\hline & ENF & 6 & 54.55 & 0 & 0.00 & 5 & 45.45 \\
\hline & LEV & 6 & 54.55 & 0 & 0.00 & 5 & 45.45 \\
\hline & GAT & 6 & 54.55 & 1 & 9.09 & 4 & 36.36 \\
\hline & OFX & 6 & 54.55 & 1 & 9.09 & 4 & 36.36 \\
\hline & CIP & 7 & 63.64 & 0 & 0.00 & 4 & 36.36 \\
\hline & HOR & 2 & 18.18 & 0 & 0.00 & 9 & 81.82 \\
\hline
\end{tabular}

In Quinolone/Fluoroquinolones; the isolates were most Among the Quinolonelfluoroquinolone; isolates were resistant towards Nalidixic acid $(72.73 \%)$ followed by Ciprofloxacin $63.64 \%$ and $81.82 \%$ sensitive for Norfloxacin. most sensitive towards Norfloxacin $(100 \%)$ followed by Moxifloxacin, Enrofloxacin, Levofloxacin, Gatifloxacin and Ciprofloxacin (80\%).

Table 6. QuinolonelFluoroquinolone sensitivity pattern of $C$. freundii

\begin{tabular}{|c|c|c|c|c|c|c|c|}
\hline \multicolumn{8}{|l|}{ Citrobacter freundii $(\mathrm{n}=9)$} \\
\hline \multirow{3}{*}{$\begin{array}{l}\text { Antbiotics group } \\
\text { Quinolone'Fluoroquinol } \\
\text { ones }\end{array}$} & \multirow{3}{*}{\begin{tabular}{|l} 
Antibiotic \\
HA
\end{tabular}} & \multicolumn{2}{|l|}{ Res is tant } & \multicolumn{2}{|l|}{ Intermediate } & \multicolumn{2}{|l|}{ Sensitive } \\
\hline & & Isolates & $\%$ & Eolates & $\%$ & Isolates & $\%$ \\
\hline & & 4 & 80 & 0 & 0 & 1 & 20 \\
\hline & $\mathrm{MFX}$ & 1 & 20 & 0 & 0 & 4 & 80 \\
\hline & ENF & 1 & 20 & 0 & 0 & 4 & 80 \\
\hline & LEV & 1 & 20 & 0 & 0 & 4 & 80 \\
\hline & GAT & 1 & 20 & 0 & 0 & 4 & 80 \\
\hline & OFX & 1 & 20 & 1 & 20 & 3 & 60 \\
\hline & CIP & 1 & 20 & 0 & 0 & 4 & 80 \\
\hline & HOR & 0 & 0 & 0 & 0 & 5 & 100 \\
\hline
\end{tabular}

Table 7. QuinolonelFluoroquinolone sensitivity pattern of E. cloaecae isolates

\begin{tabular}{|c|c|c|c|c|c|c|c|}
\hline \multicolumn{8}{|c|}{ Enter roater cloaecas ( $\mathrm{r}=4)$} \\
\hline Antibiotic's group & Antibiotic & Resistart & & Intermediate & & Sensitive & \\
\hline \multirow{9}{*}{$\begin{array}{l}\text { Quinolone'Fluoroquin } \\
\text { olones }\end{array}$} & & Is olates & $\%$ & Is olates & $\%$ & Isolates & $\%$ \\
\hline & WA & 2 & 50 & 0 & 0 & 2 & 50 \\
\hline & $\mathrm{MFX}$ & 1 & 25 & 1 & 25 & 2 & 50 \\
\hline & ENF & 1 & 25 & 0 & 0 & 3 & 75 \\
\hline & LEV & 2 & 50 & 0 & 0 & 2 & 50 \\
\hline & GAI & 1 & 25 & 0 & 0 & 3 & 75 \\
\hline & OFX & 1 & 25 & 2 & 50 & 1 & 25 \\
\hline & CIP & 1 & 25 & 0 & 0 & 3 & 75 \\
\hline & $\mathrm{NOR}$ & 0 & 0 & 0 & 0 & 4 & مח1 \\
\hline
\end{tabular}


Isolates were $100 \%$ sensitive towards Norfloxacin, while towards Enrofloxacin, Gatifloxacin and Ciprofloxacin they were $75 \%$ sensitive.

In quinolone/fluoroquinolone group of antibiotics, 6 isolates were resistant to Nalidixic acid (75\%). Moreover,Moxifloxacin and Ofloxacin showed 50\% resistivity, while towards Gatifloxacin, Levofloxacin and Norfloxacin were least resistant.

Table 8. OuinolonelFluoroquinolone sensitivity pattern of $P$. aeruginosa isolates

\begin{tabular}{|c|c|c|c|c|c|c|c|}
\hline \multicolumn{8}{|c|}{ Pseudomonas aeruginosa $(\mathrm{n}=8)$} \\
\hline \multirow{3}{*}{$\begin{array}{l}\text { Antibiotics } \\
\text { group } \\
\text { Quinolonelfluo } \\
\text { roquinolone }\end{array}$} & \multirow[t]{2}{*}{ Antibiotic } & \multicolumn{2}{|l|}{ Resistant } & \multicolumn{2}{|l|}{ Inte rmediate } & \multicolumn{2}{|l|}{ Sensitive } \\
\hline & & Isolates & $\%$ & Isolates & $\%$ & Isolates & $\%$ \\
\hline & NA & 6 & 7500 & 0 & 0 & 2 & 25.00 \\
\hline & MFX & 4 & 50.00 & 1 & 12.5 & 3 & 37.50 \\
\hline & $\mathrm{ENF}$ & 3 & 3750 & 0 & 0 & 5 & 62.50 \\
\hline & LEV & 2 & 2500 & 0 & 0 & 6 & 75.00 \\
\hline & $\mathrm{GAT}$ & 2 & 2500 & 0 & 0 & 6 & 75.00 \\
\hline & OFX & 4 & 50.00 & 0 & 0 & 4 & 50.00 \\
\hline & CIP & 3 & 3750 & 0 & 0 & 5 & 62.50 \\
\hline & NOR & 2 & 2500 & 0 & 0 & 6 & 75.00 \\
\hline
\end{tabular}

Table 9.QuinolonelFluoroquinolone sensitivity pattern of Acinetobacter spp. isolates

\begin{tabular}{|c|c|c|c|c|c|c|c|}
\hline \multirow[t]{2}{*}{$\begin{array}{l}\text { Acineto bacter spp. }(\mathrm{n}=2) \\
\text { Antibio tics group }\end{array}$} & \multirow[t]{2}{*}{ Antibiotic } & \multicolumn{2}{|l|}{ Resistant } & \multicolumn{2}{|c|}{ Intermediate } & \multicolumn{2}{|c|}{ Sensitive } \\
\hline & & Isolates & $\%$ & Isolates & $\%$ & Isolates & $\%$ \\
\hline \multirow[t]{8}{*}{ Quinolonelfluoroquinolone } & NA & 2 & 100 & 1 & 50 & 0 & 0 \\
\hline & MFX & 1 & 50 & 0 & 0 & 0 & 0 \\
\hline & ENF & 1 & 50 & 0 & 0 & 1 & 50 \\
\hline & LEV & 1 & 50 & 0 & 0 & 1 & 50 \\
\hline & GAT & 1 & 50 & 0 & 0 & 1 & 50 \\
\hline & OFX & 1 & 50 & 0 & 0 & 1 & 50 \\
\hline & CIP & 1 & 50 & 0 & 0 & 1 & 50 \\
\hline & NOR & 0 & 0 & 1 & 50 & 1 & 50 \\
\hline
\end{tabular}

In Acinetobacter spp.; $100 \%$ isolates showed resistance to Nalidixic acid and $0 \%$ towards Norfloxacin in Quinolone/fluoroquinolones.

In the present study, among 252 bacterial isolates; 155 were Gram negative rods. In a similar study by (Shrestha 2005) reported higher growth rate of gram negative rods.

Among 62 Gram negative isolates subjected for study, P. mirabilis (27.42\%), P. vulgaris (11.29\%), K. oxytoca (12.90\%), K. pneumoniae (17.75\%), C. freundii $(8.06 \%)$, E. cloaecae (6.45\%), P. aeruginosa (12.90\%) and Acinetobacter spp. (3.23\%). Similar results were reported by several authors (Gautam et al.1997, Manandhar et al. 2005, Chhetri et al. 2001, Jha \& Bapat 2005 Dhakal 1999, Farrell et al. 2003).

In a study done by Fluit et al. (2004) in Europe found, Klebsiella spp. 7\%, Proteus spp. 7\%, P. aeruginosa 7\%, and Enterobacter spp. 5\%. In a study done by (Obi et al. 1996) in Africa among 10 species of bacteria, the distribution of gram negative and gram positive bacteria were $88.5 \%$ and $9.7 \%$ respectively in UTI positive samples. Proteus mirabilis is the commonest organism isolated. In Proteus mirabilis high sensitivity i.e. $82.35 \%, 70.59 \%$ and $76.47 \%$ for norfloxacin, ciprofloxacin and gatifloxacin .In fluoroquinolone group of antibiotics Proteus vulgaris was found to be most sensitive for norfloxacin i.e. 
$71.43 \%$. Klebsiella pneumonia is one of the isolate which was used for sensitivity pattern of variety of quinolone/fluoroquinolone antibiotics and found to be sensitive to norfloxacin (81.82\%), while enrofloxacin and levofloxacin both were found to be $45.45 \%$ sensitive towards these isolates. Nalidixic acid shows $72.73 \%$ resistant for the isolate. Klebsiella oxytoca were found $37.5 \%$ resistanct to nalidixic acid, moxifloxacin, enrofloxacin, levofloxacin, gatifloxacin, ofloxacillin and ciprofloxacin while norfloxacin (75\%) was found to be effective one among them. The Pseudomonas aeruginosa were also isolated. Similar result was obtained by (Kosakai et al. 1990). The study performed by different person at different places found that $P$. aeruginosa affect the urinary bladder and is considered as primary pathogens in compromised host (Manandhar et al. 2005) and uncomplicated urinary tract infection (Gautam et al. 1997) Pseudomonas aerugenosa was $75 \%$ resistant to Nalidixic acid, 75\% sensitive Norfloxacin, Gatifloxacin and Levofloxacin. Enterobacter cloaecae was not found resistant to norfloxacin and $50 \%$ of the isolates were found to be resisatant for nalidixic acid, moxifloxacin and levofloxacin. For Citrobacter freundii norfloxacin was $100 \%$ sensitive while ths same isolates were subjected for the sensitivity pattern towards moxifloxacin, enrofloxacin, levofloxacin, gatifloxacin, ofloxacin, ciprofloxacin and found $20 \%$ resistant nalidixic acid shows $80 \%$ resistant to the given isolates.

Among fluoroquinolones, norfloxacin was found to be $50 \%$ sensitive, $50 \%$ intermediate and $0 \%$ resistant for the isolates.In quinolone group; nalidixic acid was $100 \%$ resistant. In the present study, norfloxacin was seen to be effective while nalidixic acid was more resistant antibiotic, similar study performed by (Barrette et al. 1999 ) in Britain found that $98.9 \%$ of all isolates were sensitive to norfloxacin and to ciprofloxacin. Norfloxacin was most sensitive one in this study which was also similar in (Maigaord et al. 1978). Overall fluoroquinolone resistance was near $23.0 \%$, but this rate varied significantly according to sex, age, type of urinary infection and geographic region (Andreu et al. 2005).

Among 62 Gram negative isolates other than E.coli subjected for study, P. mirabilis $(27.42 \%)$, P. vulgaris (11.29\%), K. oxytoca $(12.90 \%)$, K. pneumoniae (17.75\%), C. freundii (8.06\%), E. cloaecae (6.45\%), P. aeruginosa (12.90\%), Acinetobacter spp. (3.23\%).
Altogether eight types of antibiotics belonging with quinolone/fluoroquinolone group (nalidixicacid, ciprofloxacin, ofloxacin, norfloxacin, gatifloxacin, levofloxacin, enrofloxacin, moxifloxacin) were used in this study. Of them, norfloxacin was found most sensitive and nalidixic acid was most resistant against Gram negative isolates. This indicates that norfloxacin when recommended for individuals of corresponding UTI would be the better antibiotic for treatment.

\section{Acknowledgements}

We would also like to extend our respect to Dr. Geeta Shakya, Director, Mr. Bishnu Prasad Upadhaya, Microbiologist and all the laboratory staff of NPHL. Our cordial thanks go to Mr. Shyam Mishra, Medical Technologist, Medicare Hospital and Ms. Nisha Shrestha, Medical Technologist, Blue-Cross Hospital, for their great help during bacterial urine isolates collection from those hospitals. We express our heartiest gratitude to our friend Hira Pokhrel for her great support during laboratory work. Our sincere thank go to Mr. Amrit Acharya, Mr. Prabin Shakya and Ms. Bandana Subedi,for their help.

\section{References}

Andreu, A., J.I. Alos, M .Gobernado, F. Marco, M. Rosa and J.A. Garcia-Rodriguez. 2005. Etiology and antimicrobial susceptibility among uropathogens causing community-acquired lower urinary tract infections: a nationwide surveillance study. Enferm Infec. Microbiol Clin 23:4-9

Barrett, S.P., M.A. Savage, M. P. Rebec, A. Guyot, N. Andrews and S.B. Shrimpton. 1999. Antibiotic sensitivity of bacteria associated with communityacquired urinary tract infection in Britain. J. Antimicrob Chemother. 44:359-365

Cheesbrough, M. 2000. District laboratory practice in tropical countries. Cambridge University Press, Pp.146-159.

Chhetri, P.K., S.K. Rai, U.N. Pathak, J.B. Thapa, K.C. Devkota, B. Shrestha and R.R.Shrestha. 2001. Retrospective study on urinary tract infection at Nepal Medical College Teaching Hospital, Kathmandu. Nepal Med. ZCollege J. 3:83-85

Collee, J.G., A.G. Fraser, B.P. Marmion and A. Simmons. 1996. Mackie and McCartney practical medical microbiology. 14th ed. Churchill Livingstone, New York, Pp. 84-90.

Denyer, S.P., N.A.Hodges and S.P.Gorman. 2007. Hugo and Russel's Pharmaceuticals microbiology. $7^{\text {th }}$ ed. Blackwell Publishing Company, India. Pp. 202230,240-242. 
Bharat Sapkota et al/Susceptibility Pattern of Gram.

Dhakal, B.K., B.M. Pokharel and S.R.Basnyat. 1999. A prospective study of urinary tract infection based on culture and direct microscopy of urine along with the antibiotic sensitivity test of urinary pathogen. M.Sc. dissertation submitted to the Central Department of Microbiology, T.U, Kathmandu.

Farrel, D.J., I. Morrisey, D.Rubies, M. Robbins and D. Felmingham. 2003. A UK multicentre study of the antimicrobial susceptibility of bacterial pathogens causing. UTI. J. Infect. 46:94-100.

Fluit, A.C., M.E. Jones, J.S. Franz, A. Jacques, R. Gupta and J. Verhoef. 2004. Antimicrobial resistance among urinary tract infection UTI isolates in Europe: results from the sentry Antimicrobial Surveillance. Ethiop. Med. J. 7(2):147-152

Forbes, B.A., D.F. Sahm and A.S. Weissfeld. 2002. Bailey and Scott's diagnostic Microbiology. $11^{\text {th }}$ ed. Mosby Inc; USA. pp 928-937

Fowler, J.E. and M. Mariano. 1990. Immunologic response of the prostate to bacteriuria and bacterial prostates: antigen specific immunoglobulin in men with bacterial prostatitis. J Urol. 131:363

Gautam, K., B.M. Pokharel and A.P. Sharma. 1997. Prevalence of urinary tract infection on children. MSc. dissertation Central Department of Microbiology, T.U, Kathmandu.

Jha, N. and S.K. Bapat. 2005. A study of sensitivity and resistance of pathogenic microorganisms causing UTI in Kathmandu Valley. KUMJ 3:123-129.

Lauren, B.V., J.M. Merry, K.M. Sonia , B.H. Lori, S. Richard, J.H. Richard, R.J. Javier, V. James, S. David and Z. Lynn . 2009. Relationship among ciprofloxacin, gatifloxacin, levofloxacin and norfloxacin MICs for fluoroquinolone resistant Escherichia coli clinical isolates. J Antimicrob Agents Chemother. 53:229-234

Leigh, D.A. 1990. UTI. In: Topely and Wilson's Principles of Bacteriology, Virology and Immunity, Bacterial
Diseases, (Eds. G.R. Smith \& Easmon CSF), $8^{\text {th }}$ ed. Frome and London: Butler and Tanner Ltd. pp 197214.

Maigaard, S., D. Barbaro, J.P. Luby and P.A. Mackowiak. 1989. Ciprofloxacin for methicillin resistant Staphylococcus aureus infection. J. Antimicrob. Agents Chemother. 33:128-130.

Manandhar, T., B.M. Pokharel and P. Ghimire P. 2005. Antibiotic susceptibility profile of bacterial pathogens in urinary tract infection with special reference to extended spectrum beta lactamase (ESBL) producing strains. MSc. dissertation. Central Department of Microbiology, T.U, Kathmandu.

Obi, C.L., A. Tarupiwa and C. Simango .1996. Scope of urinary pathogens isolated in the public health bacteriology laboratory. Harare: Antibiotic susceptibility patterns of isolates and incidence of haemolytic bacteria. Central African J. Med. 42(8): 244-249.

Sapkota, B., R.K. Bhandari and B.R.Tiwari. 2014. Prevalence of gram positive bacterial infection among patients of urinary tract infection and emergence of methicillin resistent Staphylococcus aureus:Academic View: J. TUTA, Tri Chandra Unit 5:18-23.

Shrestha, D., B. Shrestha and B. Lekhak. 2005. Microbiology of urinary tract infection and the prevalence of multidrug-resistant strains among the bacterial pathogens. MSc. dessertation. Central Department of Microbiology, T.U, Kathmandu.

Stamm, W.E. 2003. Urinary tract infections and pyelonephritis. In: Harrison's Principles of Internal Medicine. (Eds. E. Braunwald, S.L. Hauser, A.S. Fauci , D.L. Longo , D.L. Kasper and J.L. Jameson $15^{\text {th }}$ ed. McGraw Hill companies, Inc 2:pp1620-1623

Vandepitte, J., J.Verhaegen, K. Engbaek, P. Rohner, P. Piot and C.C. Heuck. 2003. Basic laboratory procedures in clinical bacteriology. WHO. ISBN 924154545 
Nepal Journal of Science and Technology Vol. 15, No.2 (2014) 77-84 